\title{
RUNOFF ESTIMATION USING SCS RUNOFF CURVE NUMBER METHOD IN CEBU ISLAND
}

\author{
Florwilyn C. Cayson ${ }^{1}$, Chito L. Patiño ${ }^{1}$, and Mary Joyce L. Flores ${ }^{1,2}$ \\ ${ }^{1}$ University of the Philippines Cebu Center for Environmental Informatics, Lahug, Cebu City, 6000, Philippines, \\ Email: fccayson@up.edu.ph \\ ${ }^{2}$ Department of Biology and Environmental Science, College of Science, University of the Philippines Cebu, Lahug, Cebu City, \\ 6000 , Philippines
}

Commission IV

KEY WORDS: Water Resource Management, Soil Conservation System (SCS) Runoff Curve Number, Runoff, Cebu

\begin{abstract}
:
Cebu, with its growing development and increasing demand for water, needs tools and inputs to efficiently understand and manage its water resources. Rainfall runoff models were developed to model surface runoff which may be used to assess water availability. Soil Conservation System (SCS) Runoff Curve Number (CN) method predicts runoff based on an empirical curve number for ungauged watersheds. This study aims to estimate the amount of runoff for the catchments of Cebu Island using the SCS-CN Runoff technique. The data needed for the application of the method in this study were rainfall distribution data, land use/land cover and soil texture for curve number assignment, LiDAR DEM for the delineation of the catchments, and supporting runoff measurements from a different runoff estimation model for assessment of the results. The collected data were prepared by assigning the mean statistics of the rainfall distribution and the composite curve number for each catchment using Geographic Information System (GIS). The calculation of the runoff was also done using the same framework. Maps representing Cebu Island's catchments' runoff estimates were produced. Since observed runoff data were unavailable, the results were verified by comparing the SCS-CN estimated runoff to the results of a physically-based distributed hydrologic and hydraulics modelling software, FLO-2D. The SCS$\mathrm{CN}$ estimations were found to coincide with the FLO-2D runoff estimates based on various statistical assessments. Although the results may have higher uncertainties due to the unavailability of observed runoff data, the SCS-CN Runoff method provided relevant results to that of a complex simulation model. Thus, the method may be applied to estimate runoff of ungauged catchments of Cebu Island, the results of which could provide relevant information for water resource management.
\end{abstract}

\section{INTRODUCTION}

\subsection{Background of the Study}

Cebu is known as an international commercial and business hub, with its capital, Cebu City as the second largest metropolis in the country. The water resource assessment for Cebu Island based on the per capita water availability per year and the ratio of projected potential water resources to demand for 2025 in Central Visayas emphasized the need to address Cebu's water shortage problem (World Bank, 2003). Cebu's water supply is dependent on surface and groundwater sources. These sources are primarily replenished by rainfall through groundwater recharge and runoff flowing into surface waters (USGS, 2017).

Runoff occurs when the amount of precipitation is greater than the infiltration rate of the ground surface. It provides information on water available to supply surface water bodies and possible groundwater recharge (USGS, 2017). With its relevance, several rainfall-runoff modelling techniques have been developed to represent the runoff process of the hydrological cycle ranging from simple computational equations to sophisticated mechanistic approaches (Sitterson, et al., 2017). Of the different rainfall-runoff models the Soil Conservation Service (SCS) Curve Number $(\mathrm{CN})$ method is widely recognized and accepted for its practicality as a soil and water conservation planning and flood control design (Ponce and Hawkins, 1996).

The SCS Runoff Curve Number method is a runoff estimation model that is principally influenced by an empirical curve number. The curve number defines the runoff potential of an area based on the hydrologic soil group, land cover type, hydrologic condition, and antecedent moisture condition (USDA, 1986).

Since the SCS-CN method originated from regional agricultural sites in the Midwest of the United States (Ponce and Hawkins, 1996), the adaptability of the method in other areas was reviewed. Shafuan et al. (2018) assessed the method's efficiency by evaluating several SCS-CN applications in the tropics. The review suggested its effectiveness as the method delivered sufficient results for the studies in the Taguibo Catchment, Rio San Pedro River Basin, and Mark-Hiao in the Philippines, Mexico and Laos, respectively (Shafuan et al. 2018). In addition, different hydrological modelling systems that incorporates the SCS-CN method for the computation of precipitation loss and the empirical characterization of the soil and ground cover properties have been adapted to: evaluate water resources resiliency (Marteleira et al., 2018); to determine land cover change impacts to water supply (Caja et al., 2018); and to assess the hydrologic behaviour of a watershed in response to climate and land cover changes (Arceo et al., 2018) in the Philippines.

The studies for the precipitation loss and excess computations and the runoff property characterizations through the SCS-CN method in the Philippines were incorporated in semi-distributed and distributed physically based models. These types of models commonly require multiple parameters and observed measurements for calibration which are usually unavailable and requires extensive time and manpower to collect (Sitterson; et al., 2017). Also, the execution time of these types of models for a 
large area is immoderate (Sitterson- et al., 2017). Although complex models provide more complete and spatially variable results, for the purpose of determining runoff depth, a simple empirical model can be used.

\subsection{Objective of the Study}

To provide complementing inputs for water resource management for a large area, this study employs the SCS Runoff $\mathrm{CN}$ method to estimate runoff at a catchment-scale for the catchments in Cebu Island. Estimating runoff at a catchmentscale in response to rainfall events for the study area could provide relevant information to better understand and manage water resources.

\subsection{Study Area}

The study area (Fig. 1) is in the central part of the Philippines' Visayas group of islands. Its climate is tropical which can be classified into two major seasons, wet and dry. The area's terrain is characterized by narrow coastlines, limestone plateaus, coastal plains, rolling hills, and rugged mountain ranges covering the northern and southern part of the island as described by Britannica (2016). According to the same source, the area's topography is depicted to have its highest mountains at over 1000 meters and flat tracts can be found mostly on the northern part of the island.

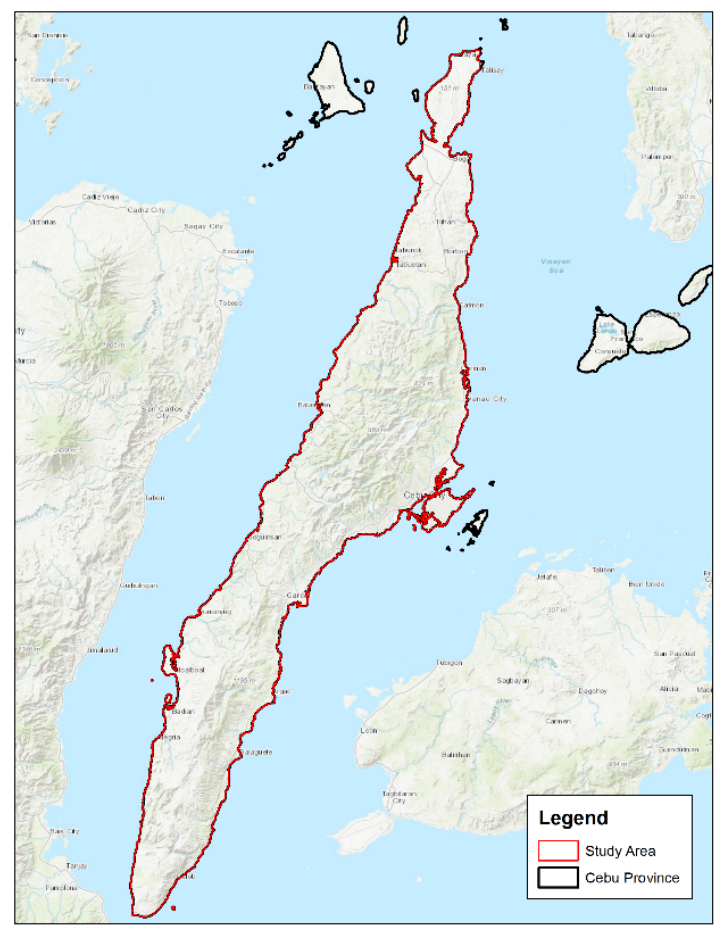

Figure 1. Map of the study area

\section{METHODOLOGY}

This chapter discusses the process of data preprocessing and the computation of runoff estimates for the catchments of Cebu Island using SCS-CN Runoff method in Arcmap 10.1.

\subsection{Data Collection and Preparation}

The catchments were delineated from a 10-meter resolution Light Detection and Ranging (LiDAR) Digital Terrain Model (DTM) using a watershed delineation framework compiled by $\mathrm{Al}$ Duncan, a UK Geomatics Specialist.

To determine a composite curve number for a catchment, the thematic maps for Cebu's soil from the Bureau of Soils and Water Management (BSWM) and land use/land cover from the National Mapping and Resource Information Authority (NAMRIA, 2015) were collected. These maps were joined by intersection to produce a map where each land cover class was assigned a hydrologic soil group.

The rainfall data with a duration of 24 hours for the 5-year, 25year, and 100-year return periods were sourced from the Philippine Atmospheric, Geophysical, and Astronomical Services Administration (PAGASA). Assigning the rainfall amount for each catchment was done by performing zonal statistics to the rainfall distribution maps.

\subsection{SCS-CN Runoff Estimation}

Runoff was estimated using the SCS Runoff CN Method which relies on a composite curve number of an average antecedent moisture condition, assigned to each catchment and rainfall depth for the 5-year, 25-year, and 100-year return periods. The method incorporated the runoff properties of the catchment by integrating soil and land use information for an average antecedent moisture condition.

2.2.1 Determining the Curve Number: For each catchment, the runoff properties were characterized by an empirical curve number derived from the soil and ground cover. The soil parameter was defined by the hydrologic soil group (HSG), determined by the soil texture. The HSG for the different soil textures is presented in Table 1 .

Table 1. Hydrologic Soil Group Description (USDA, 1986)

\begin{tabular}{|c|c|}
\hline Soil Group & Description \\
\hline A & Sand, loamy sand or sandy loam \\
B & Silt loam or loam \\
C & Sandy clay loam \\
D & Clay Loam, silty clay loam, sandy clay, silty \\
& clay, or clay \\
\hline
\end{tabular}

The curve number for an average antecedent moisture condition for the different soil and ground cover combinations of the study area was determined based on the classifications in Table 2 .

Table 2. Curve numbers for land cover classes and soil groups (Quijano et al., 2014)

\begin{tabular}{|l|c|c|c|c|}
\hline \multirow{2}{*}{ Land Use/Land Cover } & \multicolumn{4}{|c|}{ Hydrologic Soil Group } \\
\cline { 2 - 5 } & A & B & C & D \\
\hline Annual Crop & 67 & 78 & 85 & 88 \\
Brush/Shrubs & 30 & 48 & 65 & 73 \\
Fishpond & 99 & 99 & 99 & 99 \\
Built-up & 89 & 92 & 94 & 93 \\
Grassland & 30 & 58 & 71 & 78 \\
Inland Water & 99 & 99 & 99 & 99 \\
Mangrove Forest & 98 & 98 & 98 & 98 \\
Marshland/Swamp & 72 & 81 & 88 & 91 \\
Open Forest & 36 & 60 & 79 & 79 \\
Open/Barren & 63 & 77 & 85 & 88 \\
Perennial Crop & 45 & 66 & 77 & 83 \\
\hline
\end{tabular}


To determine a composite curve number for each catchment, curve number weighing, the process of summing the product of the curve numbers and its fraction of the total catchment area was performed. This procedure was defined by the equation (Singh and Satapathy, 2017):

$$
C N_{w}=\sum_{i=1}^{n} C N_{i} * A_{i} / A
$$

where $\quad C N_{w}=$ weighted curve number

$A_{i}=$ area with the curve number, $C N_{i}$

$A=$ total area of the catchment

The composite curve number was derived by rounding the $C N_{w}$ off to the nearest whole number.

2.2.2 Runoff Estimation: The estimation of runoff through the SCS Runoff CN method was calculated by implementing the following equations (USDA, 1986):

$$
Q=\left(P-I_{a}\right)^{2} /\left(P-I_{a}\right)+S
$$

$$
\text { where } \begin{aligned}
& Q=\operatorname{runoff}(\mathrm{mm}) \\
& \mathrm{P}=\text { rainfall }(\mathrm{mm}) \\
& \mathrm{S}=\text { potential maximum retention }(\mathrm{mm}) \\
& I_{a}=\text { initial abstraction }
\end{aligned}
$$

The equation was performed when the precipitation depth was greater than the initial abstraction otherwise, runoff $(Q)$ was equated to zero.

Initial abstraction $\left(I_{a}\right)$ represented all the losses before the beginning of runoff. It was calculated through the equation:

$$
\begin{array}{ll} 
& I_{a}=0.2 S(3) \\
\text { where } & I_{a}=\text { initial abstraction } \\
\mathrm{S}=\text { potential maximum retention }
\end{array}
$$

The potential maximum retention, $\mathrm{S}$ was related to the curve number of the catchment. This relationship was defined by the equation:

$$
S=25400 / C N-254
$$

where $S=$ potential maximum retention $(\mathrm{mm})$

$$
C N=\text { curve number }
$$

2.3 Model Comparison: To assess the efficiency of the method to estimate runoff for each catchment, the runoff results of a commercial hydrologic and hydraulics modelling software called FLO-2D, which used the Green-Ampt equation for its infiltration function, was compared to the SCS-CN runoff estimates for the same rainfall depths. According the FLO-2D documentation (2011), the runoff generated from a simulation can be computed by subtracting the overland infiltrated and intercepted water from the total rainfall.

To uphold consistency with the conditions simulated in the FLO2D model, the SCS-CN method parameters where calibrated to satisfy the zero initial abstraction and the 0.99 saturated soil configuration of FLO-2D. Curve numbers were calibrated to represent a saturated soil moisture condition and the initial abstraction was calibrated to 0 which is based on the assumption of Shaw and Walter (2009).
To calibrate the average condition curve number to a saturated condition, the following equation by Singh and Satapathy (2017) was used:

$$
C N_{\text {III }}=C N_{I I} / 0.427+0.00573 C N_{I I} \quad \text { (5) }
$$

where $\quad C N_{I I I}=$ curve number for a saturated soil condition

$C N_{I I}=$ curve number for an average moisture condition

To measure the efficiency of the SCS Runoff CN Method, Root Mean Square Error (RMSE), Pearson Correlation Coefficient, Nash-Sutcliffe (E), Percent Bias (PBIAS), and Observation Standard Deviation Ratio, RSR validation statistical indices were computed for the FLO-2D runoff and SCS-CN runoff estimates comparison.

\section{RESULTS AND DISCUSSION}

This chapter presents the results from the collection and preparation of data, curve number determination for the catchments and runoff estimation from the SCS Runoff $\mathrm{CN}$ method.

\subsection{Watershed Delineation from LiDAR DTM}

The watershed delineation process mapped 438 water basins over the study area. The largest catchment delineated was 81.089 sq. $\mathrm{km}$. while the smallest catchment was $0.228 \mathrm{sq}$. $\mathrm{km}$. The mean area of the basins was 10.769 sq. $\mathrm{km}$. These catchments were designated as an area of land where rain is collected naturally by the landscape and drains off into a common channel. The delineated catchments are illustrated in Figure 2.

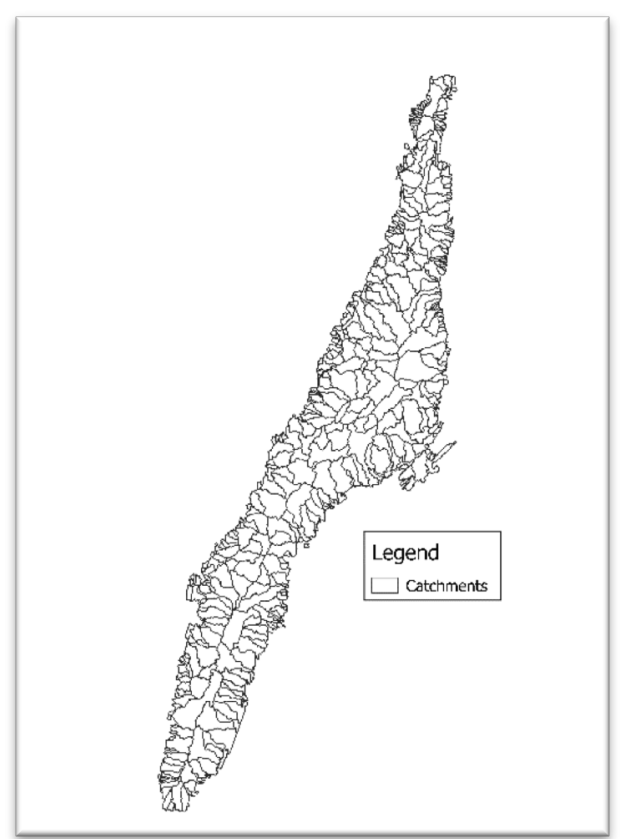

Figure 2. Catchments mapped from watershed delineation framework

\subsection{Curve Number Assignment}

Based on the soil data provided by the BSWM, the soil texture was defined for the different soil classes of the study area. The spatial distribution of the soil texture classes is shown in Figure 3. 
The study area was dominantly characterized by the HSG D (clay loam, silty clay loam, sandy clay, silty clay, clay) which covers $97 \%$ of the total area. Meanwhile, the HSGs A (sand, loamy sand, sandy loam) and B (silt loam, loam) cover the remaining 3\% of the study area and are situated on its perimeters.

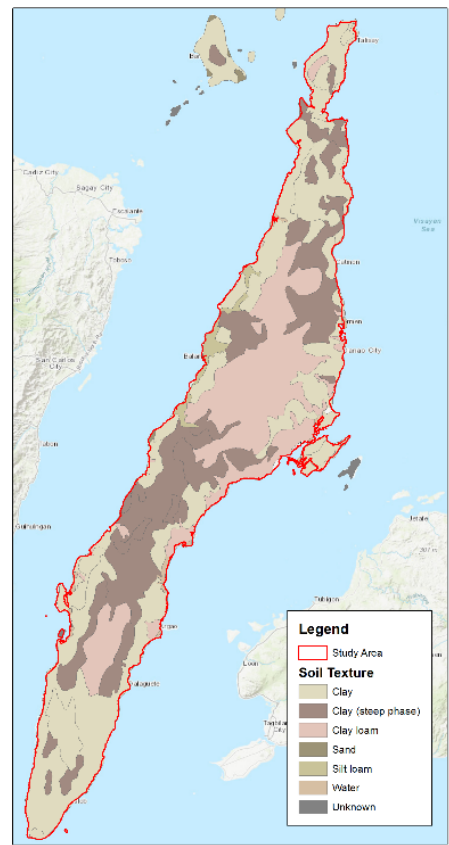

Figure 3. Soil Texture Map

HSG is defined by the grading of a soil's runoff potential and water transmission rate. HSG D soils have a high runoff potential and a low water transmission rate, HSG A soils have a low runoff potential and a high water transmission rate, while HSG B soils have a moderate runoff potential and a moderate water transmission rate (USDA, 1986).

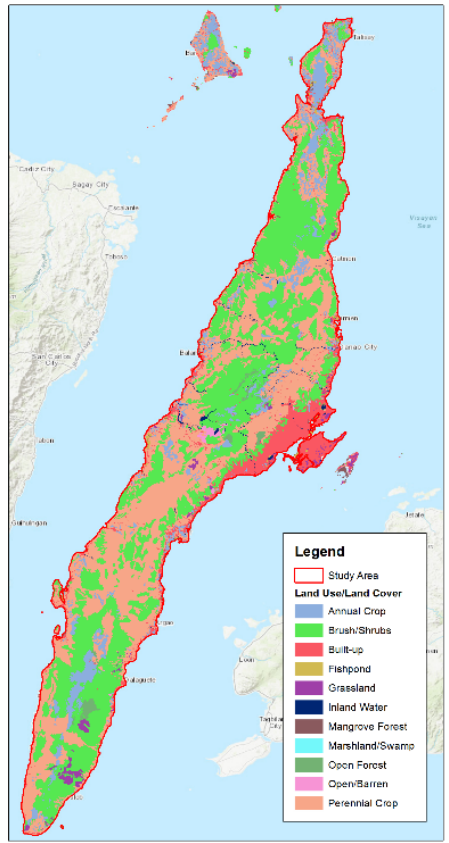

Figure 4. Land Use/Land Cover Map
Another determinant of the curve number was the land use/land cover of the study area. The land cover/land use map sourced from NAMRIA is presented in Figure 4.

The integration of the land use/land cover classes with the HSG produced the curve numbers for each land cover and soil group intersection. From here, a composite curve number was computed by curve number weighing for each catchment. The computed composite curve number represented an average antecedent moisture condition. This value was retained since this configuration was considered ideal for design rainfall events and simulation purposes (USDA, 1986). The composite curve number map is illustrated in Figure 5.

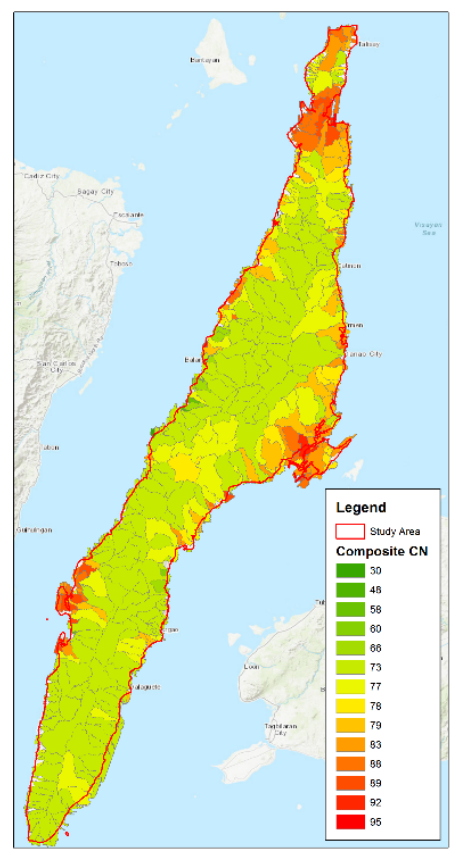

Figure 5. Composite Curve Number Map (AMC II)

The curve numbers ranged from 30 to 95 . These values represented the runoff potential of a catchment. Higher curve numbers suggest a high potential for runoff. The maximum curve number 95, characterized built-up areas with an HSG D which had the highest runoff potential. Meanwhile, brushlands with an HSG A and represented by the curve number 30, had the lowest runoff potential. Majority of the catchments, however, had a curve number of 73 characterizing brushlands with an HSG D. This curve number was assigned mostly to the catchments situated in the mountainous parts of the study area. Curve numbers assigned to the catchments in dense built-up areas and marshlands were relatively high. Catchments with higher curve numbers are expected to have high runoff depths. However, the computation for the runoff depth also depend on how much rain falls into a catchment.

3.3 Runoff Estimations for the 5-year, 25-year, 50-year, and 100-year Rainfall Return Periods

Figure 6 shows the runoff estimates from a 24-hour rainfall duration for the 5-year, 25-year, 50-year, and 100-year return periods. 


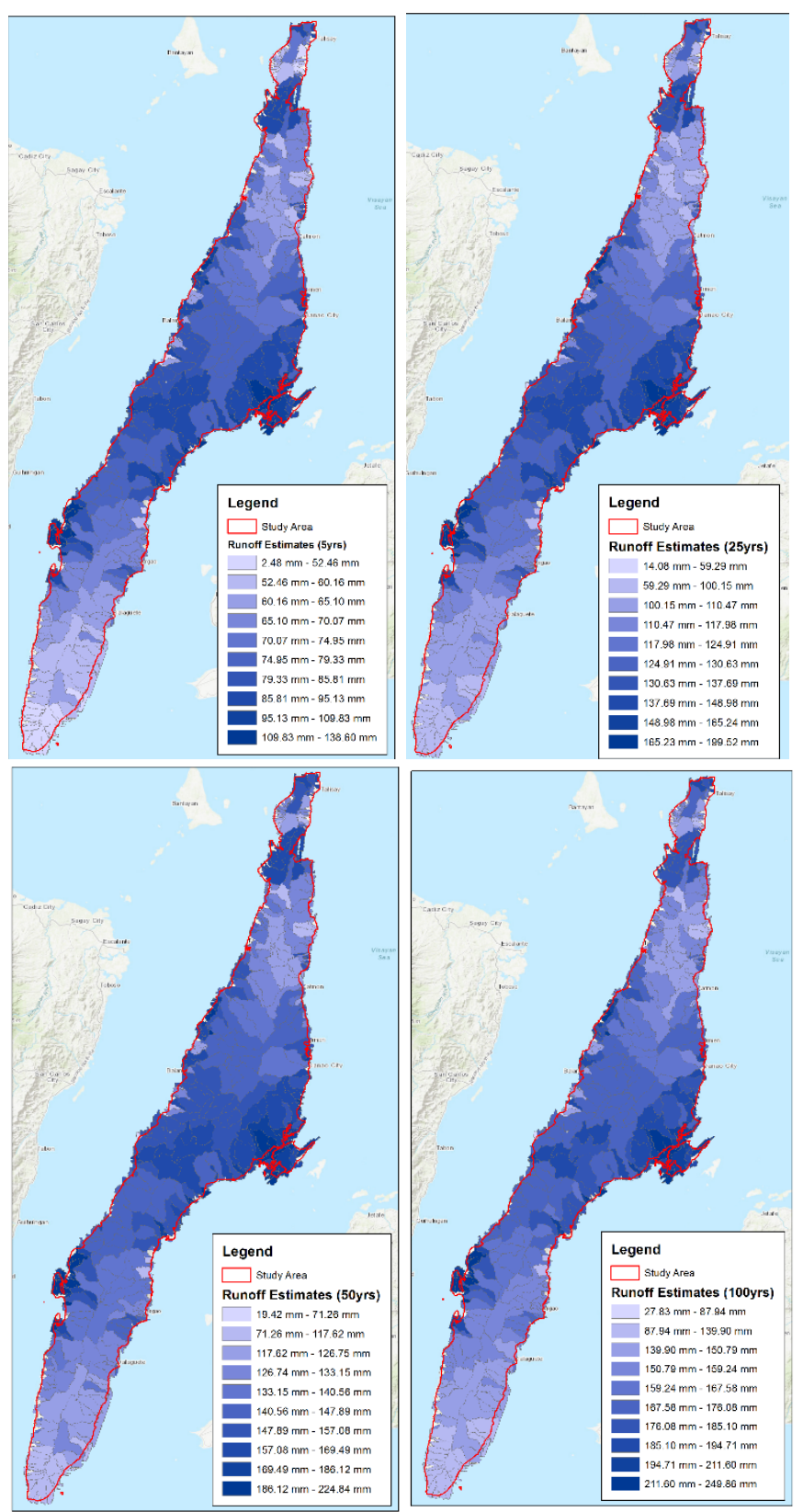

Figure 6. Runoff estimates for the 5-year, 25-year, 50-year and 100 -year return periods

Higher runoff estimates were computed from the 100-year return period while lower runoff estimates were computed for the shorter return periods. Although the rainfall distribution showed the same pattern for the different return periods, the runoff estimations derived from the SCS-CN method affected this pattern through the curve number function. This conveyed the influence of the soil type and the land cover/land use that characterized the catchment. Also, it appears that the SCS-CN method was sensitive to the curve number for the runoff estimates. The higher the curve number, the lesser the potential maximum retention resulting to a higher runoff depth of a catchment.

\subsection{Model Comparison}

To validate the capability of the SCS-CN method for runoff estimation, the estimates should have been compared to observed runoff measurements. In consideration of the limitation that there were no available observed runoff measurements comparable to the runoff estimated at a catchment-scale for the study area, the runoff computed from a FLO-2D simulation which used the Green-Ampt equation for infiltration losses for some catchments in the study area, was collated to the SCS-CN estimated runoff to verify the results in terms of consistency with other models. In addition, as the FLO-2D simulation for each catchment and rainfall event was performed in a very fine scale, computational time was very long, thus only 39 runoff measurements from different catchments and rainfall return periods were managed to be used as related values for the SCS-CN runoff estimates.

The runoff generated by FLO-2D was the difference of the rainfall depth and the overland intercepted and infiltrated water. The results of the runoff estimates for the two models can be viewed in Table 3.

Table 3. FLO-2D Runoff Output and SCS-CN Estimated Runoff

\begin{tabular}{|c|c|c|c|c|}
\hline \multirow[b]{2}{*}{$\begin{array}{l}\text { Model } \\
\text { No. }\end{array}$} & \multicolumn{3}{|c|}{ FLO-2D Results } & SCS-CN \\
\hline & $\begin{array}{l}\text { Rainfall } \\
\text { Depth }\end{array}$ & $\begin{array}{c}\text { Overland } \\
\text { Intercepted } \\
\text { and } \\
\text { Infiltrated } \\
\text { Water }\end{array}$ & $\begin{array}{l}\text { FLO- } \\
\text { 2D } \\
\text { Runoff }\end{array}$ & $\begin{array}{c}\text { SCS-CN } \\
\text { Runoff }\end{array}$ \\
\hline 1 & 136.5391 & 31.7 & 104.84 & 105.55 \\
\hline 2 & 192.6175 & 39.92 & 152.70 & 159.44 \\
\hline 3 & 239.447 & 40 & 199.45 & 205.03 \\
\hline 4 & 137.3659 & 35.64 & 101.73 & 105.07 \\
\hline 5 & 193.6494 & 41.48 & 152.17 & 158.92 \\
\hline 6 & 241.3561 & 41.16 & 200.20 & 205.41 \\
\hline 7 & 135.3587 & 29.81 & 105.55 & 104.57 \\
\hline 8 & 191.2688 & 36.12 & 155.15 & 158.29 \\
\hline 9 & 238.7163 & 34.82 & 203.90 & 204.54 \\
\hline 10 & 135.2932 & 34.22 & 101.07 & 103.31 \\
\hline 11 & 191.2201 & 40.97 & 150.25 & 156.79 \\
\hline 12 & 238.9016 & 40.9 & 198.00 & 203.17 \\
\hline 13 & 133.2024 & 26.62 & 106.58 & 102.08 \\
\hline 14 & 188.7506 & 32.42 & 156.33 & 155.30 \\
\hline 15 & 236.3907 & 31.52 & 204.87 & 201.65 \\
\hline 16 & 131.5921 & 32.56 & 99.03 & 100.84 \\
\hline 17 & 186.7779 & 40.54 & 146.24 & 153.79 \\
\hline 18 & 234.1743 & 41.09 & 193.08 & 200.12 \\
\hline 19 & 131.0953 & 29.25 & 101.85 & 99.84 \\
\hline 20 & 188.2438 & 36.61 & 151.63 & 152.56 \\
\hline 21 & 233.8209 & 35.43 & 198.39 & 198.83 \\
\hline 22 & 137.4132 & 45.09 & 92.32 & 106.12 \\
\hline 23 & 193.6779 & 51.36 & 142.32 & 160.15 \\
\hline 24 & 241.0943 & 52.21 & 188.88 & 206.35 \\
\hline 25 & 137.366 & 46.26 & 91.11 & 106.32 \\
\hline 26 & 193.6495 & 52 & 141.65 & 160.42 \\
\hline 27 & 241.3535 & 54.64 & 186.71 & 206.96 \\
\hline 28 & 136.893 & 30.06 & 106.83 & 105.91 \\
\hline 29 & 193.0772 & 36.06 & 157.02 & 159.91 \\
\hline 30 & 240.5813 & 34.25 & 206.33 & 206.26 \\
\hline 31 & 134.8281 & 26.83 & 108.00 & 104.11 \\
\hline 32 & 190.6509 & 33.38 & 157.27 & 157.76 \\
\hline 33 & 238.1698 & 31.28 & 206.89 & 204.16 \\
\hline
\end{tabular}




\begin{tabular}{|c|c|c|c|c|}
\hline 34 & 131.0949 & 31.18 & 99.91 & 100.38 \\
35 & 186.2435 & 37.59 & 148.65 & 153.24 \\
36 & 233.8204 & 35.43 & 198.39 & 199.58 \\
37 & 128.973 & 25.8 & 103.17 & 98.38 \\
38 & 183.7027 & 32.89 & 150.81 & 150.78 \\
39 & 231.192 & 30.2 & 165.68 & 197.01 \\
\hline
\end{tabular}

The results of the Pearson correlation, RMSE, NSE, PBias, and RSR indices for the comparison of the runoff computed by the two models are summarized in Table 4.

Table 4. Validation Statistics

\begin{tabular}{|c|c|}
\hline Metrics & Value \\
\hline Pearson Correlation & 0.99 \\
RMSE & 7.67 \\
Nash-Sutcliffe (NSE) & 0.96 \\
PBias & -0.17 \\
RSR & 1.152 \\
\hline
\end{tabular}

The results of the statistical assessment of between the correlation of FLO-2D simulated results and the SCS-CN method inferred efficiency because the values exhibited a positive correlation (Pearson Correlation), a minor individual difference aggregation (RMSE), a high predictive power (NSE), a negative bias close and an RSR value close to the optimal 0.

\section{LIMITATIONS AND RECOMMENDATIONS FOR FUTURE WORK}

The choice of input data for the rainfall, curve number derivation, and model verification dataset was based on data availability. Thus, observed datasets for the rainfall and runoff to profoundly rationalise the model's outputs may be taken into account.

The reliance of the method on the curve number for the runoff estimations imply its sensitivity to land cover changes. Thus, continuous calibrations to update the runoff properties of a catchment should be considered. Also, the method assumed a homogenous runoff property for an entire catchment, thus, the spatial variability at a finer scale was not considered. In addition, the initial abstraction ratio was adapted as is, hence calibration may be deliberated to signify a local characterization of an area's geologic and climatic conditions.

Although the results of the SCS Runoff CN method were verified through comparison with FLO-2D, it should be noted that both models are only representations of a system which may each encompass their own uncertainties. Thus, a better assessment may be made conducted with observed data once available.

\section{CONCLUSION}

This study utilized the SCS Runoff CN method to estimate the runoff depth of the catchments of Cebu Island. The method was implemented to provide an efficient approach to estimate runoff in response to rainfall events of a large area for water resource management of the catchments of Cebu Island.

Higher runoff estimates were produced from the 100-year return period and lower runoff estimates from the shorter return periods.
The influence of the curve number which described the runoff properties of a catchment was evident as can be observed in the variations in runoff depth even with the uniform pattern of rainfall distribution for the different return periods.

The comparison of the model to the computed runoff from FLO$2 \mathrm{D}$ showed a positive statistical relationship, a low error, and a high predictive power of the SCS-CN method when estimates were collated. These satisfactory results imply that the runoff estimations from the two models coincided very well. Thus, runoff estimations from the SCS-CN method were substantiated in relation to the physically-based and distributed representation of the hydrological process defined in FLO-2D.

The SCS Runoff CN method may be considered for the runoff estimation of Cebu Island's ungauged catchments. The results may serve as initial inputs for assessing water availability in the ungauged catchments of the study area. This could also provide relevant information for water resource management. However, the use of the SCS-CN method should be treated with caution. It may have higher uncertainties and lower accuracy because of the unavailability of observed runoff measurements for the catchments of the study area.

\section{ACKNOWLEDGEMENTS}

This research is conducted by the University of the Philippines Cebu Center for Environmental Informatics. We are grateful for the support of the Department of Science and Technology (DOST) and its Niche Centers in the Regions for R\&D (NICER) Program.

\section{REFERENCES}

Arceo, M.G.A., Cruz, R.V., Tiburan, C.J., Balatibat, J., Alibuyog, N., 2018: Modeling the Hydrologic Responses to Land Cover and Climate Changes of Selected Watersheds in the Philippines Using Soil and Water Assessment Tool (SWAT) Model. DLSU Business \& Economics Review 28(2018), 84-101.

Caja, C., Ibunes, N., Paril, J., Reyes, A., Nazareno, J., Monjardin, C., Uy, F., 2018. Effects of Land Cover Changes to the Quantity of Water Supply and Hydrologic Cycle using Water Balance Models. MATEC Web of Conferences 150, 06004. doi:10.1051/matecconf/201815006004.

FLO-2D Software, Inc., 2011. FLO-2D Model Validation for Version 2009 and Up.

Marteleira, R., Roxo M. J., Lasco, R., Coelho, P.S., 2018: Hydrological modeling to assess water resources resilience towards climate change impacts in Tacloban, Philippines. Climate, Disaster and Development Journal. doi.org/10.18783/cddj.v003.i01.a02

World Bank, 2003. Philippines - Environment monitor 2003 (English). Washington, DC: World Bank.

Ponce, V.M., Hawkins, R.H., 1996. Runoff Curve Number: Has It Reached Maturity? Journal of Hydrologic Engineering 1, 1119. doi:10.1061/(asce)1084-0699(1996)1:1(11) 
Quijano, I.P., Valenzuela J., Caredo, R.S., Patiño, C., Sinogaya, J., Vulnerability Assessment of Government Buildings in Sagay City through Flood Modeling and Mobile GIS. URL http://citeseerx.ist.psu.edu/viewdoc/download?doi=10.1.1.741.5 748\&rep=rep1\&type=pdf (accessed 9.10.19).

Shafuan, A., Faizalhakim, M., Nurhidayu, S., Kamarudin, N., 2018. SCS-CN in Tropics: Is It Reliable?. The Pertanika Journal of Scholarly Research Reviews. 3.

Shaw, S.B., Walter, M.T., 2009. Improving runoff risk estimates: Formulating runoff as a bivariate process using the SCS curve number method. Water Resources Research 45. doi:10.1029/2008wr006900.

Singh, M., Satapathy, D., 2018. Rainfall-Runoff Estimation Using SCS-CN and GIS Approach in the Kuakhai Watershed of the Mahanadi Basin of Bhubaneswar Odisha. International Journal of Emerging Research in Management and Technology 6,9. doi:10.23956/ijermt.v6i12.30

Sitterson, J., Knightes, C., Parmar R., Wolfe, K., Muche, M., Avant., 2017. An Overview of Rainfall-Runoff

Model Types. U.S. Environmental Protection Agency, Washington, DC, EPA/600/R-17/482

The Editors of Encyclopaedia Britannica, 2016. Cebu. Encyclopædia Britannica. URL https://www.britannica.com (accessed 9.10.19)

USDA, 1986. Soil Conservation Service National Engineering Handbook, USA.

USGS, 2017. "Runoff: Surface and Overland Water Runoff". Water Science School. URL https://www.usgs.gov/specialtopic/water-science-school/science/runoff-surface-andoverland-water-runoff (accessed 9.14.19). 